\title{
Fluorescence from atmospheric aerosol detected by a lidar indicates biogenic particles in the lowermost stratosphere
}

\author{
F. Immler ${ }^{1}$, D. Engelbart ${ }^{2}$, and O. Schrems ${ }^{1}$ \\ ${ }^{1}$ Alfred Wegener Institute for Polar and Marine Research, Am Handelshafen 12, 27570 Bremerhaven, Germany \\ ${ }^{2}$ German Weather Service, Meteorological Observatory Lindenberg, Am Observatorium 12, 15848 Lindenberg, Germany
}

Received: 27 July 2004 - Published in Atmos. Chem. Phys. Discuss.: 28 September 2004

Revised: 25 January 2005 - Accepted: 1 February 2005 - Published: 8 February 2005

\begin{abstract}
With a lidar system that was installed in Lindenberg/Germany, we observed in June 2003 an extended aerosol layer at $13 \mathrm{~km}$ altitude in the lowermost stratosphere. This layer created an inelastic backscatter signal that we detected with a water vapour Raman channel, but that was not produced by Raman scattering. Also, we find evidence for inelastic scattering from a smoke plume from a forest fire that we observed in the troposphere. We interpret the unexpected properties of these aerosols as fluorescence induced by the laser beam at organic components of the aerosol particles. Fluorescence from ambient aerosol had not yet been considered detectable by lidar systems. However, organic compounds such as polycyclic aromatic hydrocarbons sticking to the aerosol particles, or bioaerosol such as bacteria, spores or pollen fluoresce when excited with UV-radiation in a way that is detectable by our lidar system. Therefore, we conclude that fluorescence from organic material released by biomass burning creates, inelastic backscatter signals that we measured with our instrument and thus demonstrate a new and powerful way to characterize aerosols by a remote sensing technique. The stratospheric aerosol layer that we have observed in Lindenberg for three consecutive days is likely to be a remnant from Siberian forest fire plumes lifted across the tropopause and transported around the globe.
\end{abstract}

\section{Introduction}

Soot released by combustion into the atmosphere absorbs radiation and therefore heats the climate counteracting the cooling effect generally assigned to anthropogenic aerosols (Chung and Seinfield, 2002). Aerosol particles are released either at the Earth's surface from various sources, the crust (dust), the sea (sea salt aerosol) or by combustion processes

Correspondence to: F. Immler

(fimmler@awi-bremerhaven.de) (soot), or they form in situ by gas to particle conversion, like sulphate aerosol. While particles may enter the stratosphere in the tropics (Brock et al., 1995), the tropopause in the mid latitude efficiently suppresses tropospheric-stratospheric transport (TST) (Holton et al., 1995). However, recent observation of stratospheric aerosol layers by satellite-borne instruments and ground-based lidar suggest that strong thunderstorms are able to inject smoke from forest fires into the stratosphere at high latitudes (Fromm et al., 2000). Latest in situ measurements also proof the presence of forest fire particles in the stratosphere (Jost et al., 2004). Even though these layers are optically thin, they are highly relevant because when aerosols leave the troposphere they escape their most efficient removal mechanism which is wet scavenging and consequently their lifetimes are strongly increased. The implications of particles in the stratosphere on the radiative balance and chemistry crucially depend on their physical and chemical properties. Ground or satellite based sensors may measure the global distribution of the optical depth of aerosols but usually provide little information on the exact type and source of the particles (Kaufman et al., 2002).

Lidar is a powerful tool to investigate atmospheric aerosol since it makes it possible to measure its distribution from near to the ground up to the upper atmosphere with high vertical and temporal resolution. The different lidar techniques applicable to aerosol measurements like multi-wavelength backscatter lidar, depolarisation measurement and Raman techniques allow the determination of the particle's macroand microphysical properties to some extent. However, a precise and reliable characterization of aerosol based on lidar data which includes a description of its size distribution and chemical composition is generally hampered by the limited information available from this remote sensing techniques.

Here, we report the observation of a stratospheric aerosol layer by a ground based lidar system. Besides aerosol layers in the middle troposphere and cirrus clouds at about $12 \mathrm{~km}$, Fig. 1 shows a thin layer of particles in the lowermost

(C) 2005 Author(s). This work is licensed under a Creative Commons License. 


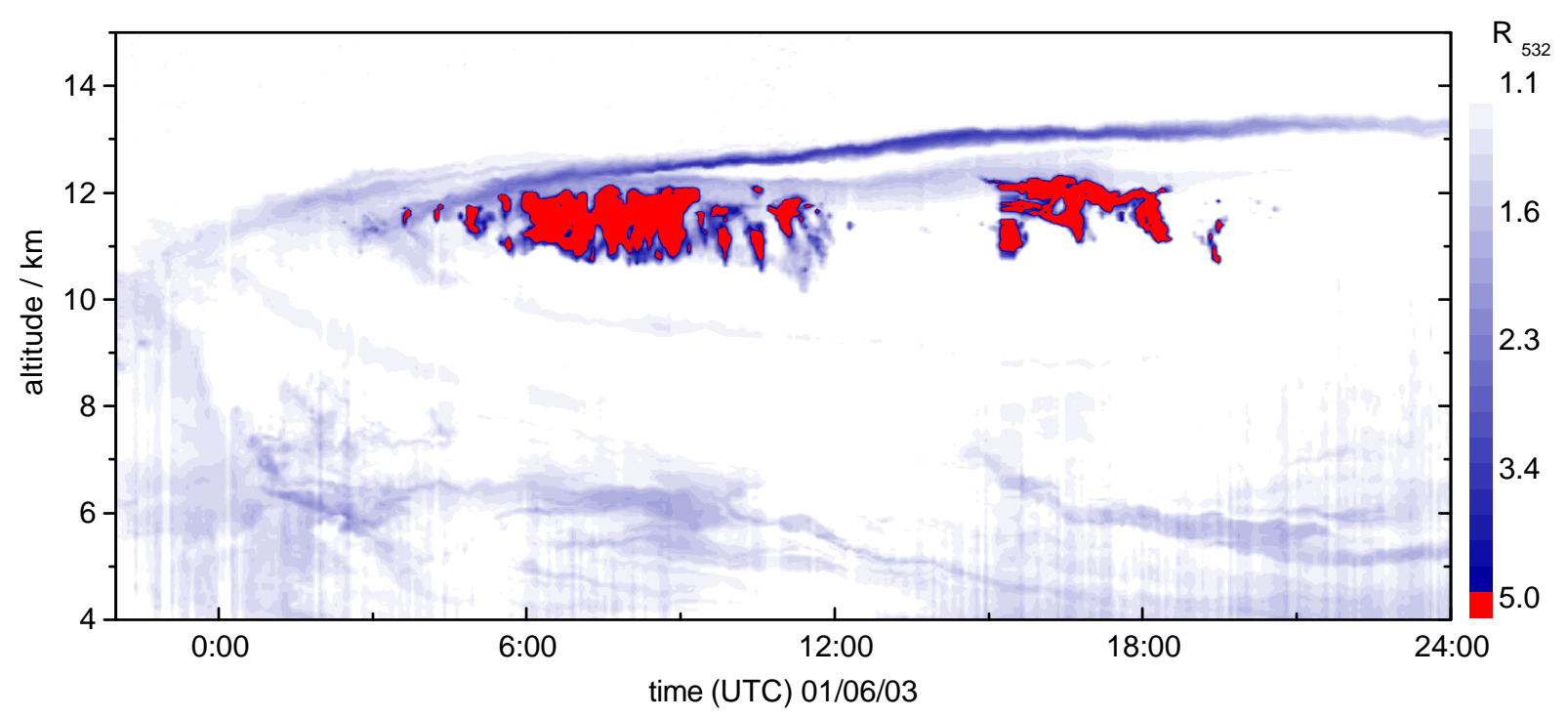

Fig. 1. Lidar backscatter ratio at $532 \mathrm{~nm}$ as a function of time and altitude from Lindenberg on 1 June 2003.

stratosphere with a backscatter ratio of about 3-4. This layer gave rise to a red shifted inelastic backscatter signal that we detected with our instrument and interpret as laser induced fluorescence (LIF) created by the aerosol particles. At first we briefly describe the methods used for this observations (Sect. 2) and the results obtained from them (Sect. 3). We will then discuss fluorescence of aerosol as a possible cause for the detected inelastic signal (Sect. 4) before we draw the corresponding conclusions in Sect. 5.

\section{Instrumentation and water vapour measurements}

The Mobile Aerosol Raman Lidar (MARL) of the Alfred Wegener Institute (AWI) is designed for measurements of aerosols and water vapour in the stratosphere and upper troposphere (Schäfer et al., 1995). It detects light backscattered by molecules and condensed matter in the atmosphere from outgoing laser beams at $532 \mathrm{~nm}$ and $355 \mathrm{~nm}$. Inelastic Raman backscatter from nitrogen is detected at $387 \mathrm{~nm}$ and $607 \mathrm{~nm}$ and allows the direct retrieval of the aerosol extinction coefficient $\alpha$ (Ansmann et al., 1992). An additional detection channel at $407 \mathrm{~nm}$ with a bandwidth of $5.7 \mathrm{~nm}$ detects the vibrational Raman scattering from $\mathrm{H}_{2} \mathrm{O}$ molecules and allows the determination of the water vapour mixing ratio profiles up to about 8 to $10 \mathrm{~km}$ at night time.

The emitter of the lidar is a Nd:YAG laser with frequency doubling and tripling, generating laser pulses with about $300 \mathrm{~mJ}$ at both $355 \mathrm{~nm}$ and $532 \mathrm{~nm}$ with a repetition rate of $30 \mathrm{~Hz}$ and a pulse duration of $8 \mathrm{~ns}$. The receiver is based on a Cassegrain telescope with $1.1 \mathrm{~m}$ aperture coupled by two fibre bundles to the 10-channel polychromator. Our system is able to perform unattended measurements and can be controlled via the internet, thus enabling us to gain a large dataset even with a minimum of manpower. Continuous data records spanning several consecutive days were achieved on occasions owing to the high degree of automation of the system.

A lidar signal measured at the wavelength $\lambda$ is proportional to the total backscatter coefficients at this wavelength $\beta_{\lambda}$ and is described by the following equation:

$P_{\lambda}(z)=\frac{C}{z^{2}} O(z) \beta_{\lambda}(z) T^{2}(z)$

$C$ summarizes all system constants like laser energy and detection efficiency and $T(z)$ is the transmission term that can be calculated by using Beer-Lambert's law:

$T(z)=\exp \left[-\int_{0}^{z} d z^{\prime}\left(\alpha^{A}\left(z^{\prime}\right)+\alpha^{M}\left(z^{\prime}\right)\right)\right]$

$\alpha^{M}$ and $\alpha^{A}$ refer to the extinction coefficients caused by molecular and particle scattering, respectively. $O(z)$ describes the geometric overlap between laser and field of view of the receiving telescope.

Inelastic scattering can be detected at the vibrational Raman lines of atmospheric gases (Melfi, 1972). The backscatter coefficient $\beta$ is in good approximation a function of the number density profile of the corresponding molecule $N(z)$ and the cross section $\sigma_{\lambda}$ for Raman scattering which we assume here to be independent on temperature. For water vapour the backscatter coefficient is then simply a function of the concentration of water molecules and the backscattering cross section which is constant throughout the atmosphere:

$\beta_{407}(z)=N^{\mathrm{H}_{2} \mathrm{O}}(z) * \sigma_{407}^{\mathrm{H}_{2} \mathrm{O}}$

Introducing this equation into the lidar Eq. (1) yields an expression describing the water vapour Raman signal measured 
30 May $2003,22: 45$ UTC

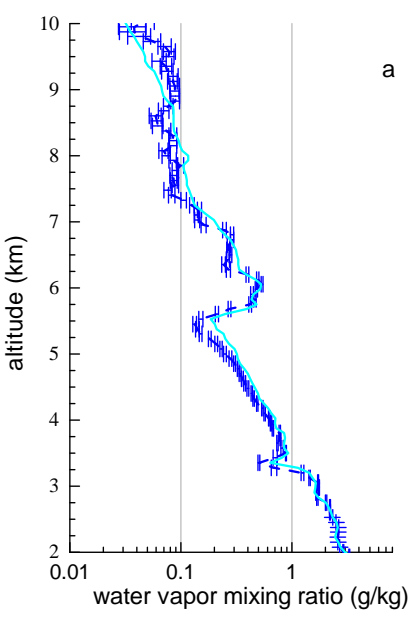

backscatter ratio at $532 \mathrm{~nm}$

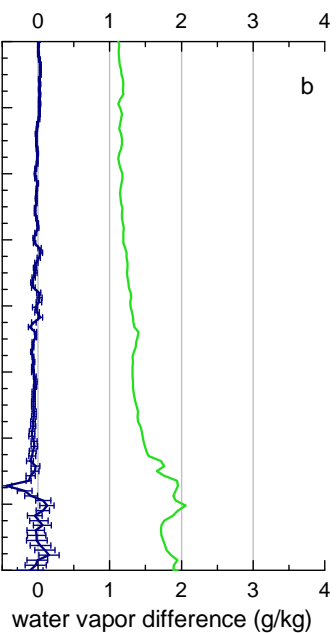

03 June 2003, 22:45 UTC

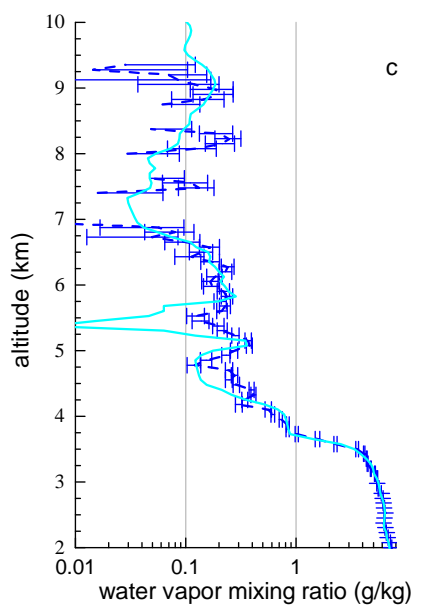

backscatter ratio @ 532 nm

$\begin{array}{lllllllll}0 & 2 & 4 & 6 & 8 & 10 & 12 & 14 & 16\end{array}$

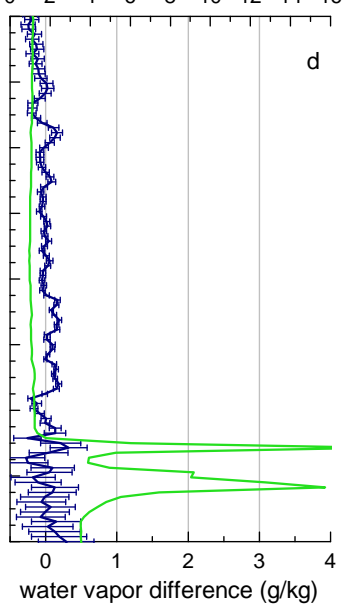

Fig. 2. Water vapour measurements by Raman lidar (blue) and radiosonde (cyan) from 30 May 2003 (a and b) and 3 June 2003 (c and d) in Lindenberg. Plot (b) and (d) show the differences of the water vapour mixing ratio between lidar and RS data. Radiosonde launch time in both cases was 22:45 UT. The green line indicates the backscatter ratio at $532 \mathrm{~nm}$ determined with the lidar. The lidar measurements are averaged over $20 \mathrm{~min}$ (about 36000 laser shots) starting at 22:47 UT on 30 May 2003 and 22:38 UT on 3 June 2003.

by a lidar. In an analogue way the Raman signal from nitrogen that is measured at $387 \mathrm{~nm}$ can be described. The ratio of the water vapour and the nitrogen Raman lidar signal is then proportional to the water vapour mixing ratio $w^{\mathrm{H}_{2} \mathrm{O}}(z)$ :

$w^{\mathrm{H}_{2} \mathrm{O}}(z)=\frac{N^{\mathrm{H}_{2} \mathrm{O}}(z) M^{\mathrm{H}_{2} \mathrm{O}} w^{N_{2}}}{N^{N_{2}}(z) M^{d r y}}=C^{\prime} \frac{P_{407}^{\mathrm{H}_{2} \mathrm{O}}(z)}{P_{387}^{N_{2}}(z)}$

$O(z)$ is the same for both lidar signals and thus cancelled. $\mathrm{MH}^{\mathrm{H}_{2} \mathrm{O}}$ and $\mathrm{M}^{d r y}$ are the molecular weights of water and dry air, respectively. The correction for the differences in the remaining transmission terms $\left(T_{407}(z) / T_{387}(z)\right)$ that was neglected in Eq. (4) is performed as described by Whiteman et al. (1992). The mixing ratio of nitrogen $w^{N_{2}}$ is constant in the altitude range of interest. However, the calibration constant $C^{\prime}$ needs to be determined by using another independent measurement of water vapour because the system constants can not be otherwise established.

The German weather service (DWD) provided Radiosonde (Vaisala RS 80) data from four daily launches at the site and these delivered a temperature and humidity profile and allowed the determination of the tropopause height. The water vapour measurement of the RS 80 sondes is based on an improved retrieval algorithm (Leiterer et al., 1997). This data served for calibrating the water vapour measurements of the lidar which is done by determining $C^{\prime}$ from Eq. (4) using the water vapour mixing ratio $w_{R S}^{\mathrm{H}_{2} \mathrm{O}}(z)$ determined from the radiosonde profile at an altitude $z_{0}$. An appropriate fit altitude $z_{0}$ is usually found in about $3-5 \mathrm{~km}$ altitude, where the aerosol load is low and the water vapour is still high. During the campaign in Lindenberg we gathered 37 occasions of coincident lidar and RS water vapour measurements. The cal- ibration constant was determined each time and varied less than $5 \%$.

The water vapour profiles from lidar measurements presented below were calibrated using lidar and radiosonde profiles measured simultaneously shortly before the events under discussion. The stability of the calibration is demonstrated in Fig. 2. On 30 May 2003 a calibration factor was determined at $2.3 \mathrm{~km}$ altitude. The differences between the lidar and the RS profiles (Fig. 2b) are low throughout the troposphere and are mainly due to the temporal variability of the water vapour profile. This calibration factor is used to determine the water vapour profile of the consecutive days. A profile calculated this way from 3 June 2004 is shown in Fig. 2c along with a simultaneously measured radiosonde profile. The differences of the two profiles are less than $0.2 \mathrm{~g} / \mathrm{kg}$ (Fig. 2d). The strong aerosol layer in the boundary layer $(<3 \mathrm{~km})$ and the starting cloud formation on its top, indicated by the strong backscatter ratio, do not significantly interfere with the water vapour measurement of the lidar.

Beside water vapour and cirrus clouds another major focus of our measurements is tropospheric aerosol. It was demonstrated during a ship-borne campaign that our system is able to detect and differentiate dust from marine particles in the troposphere (Immler and Schrems, 2003). This is possible due to the fact that the depolarisation and the wavelength dependence of the backscatter coefficient expressed as colour index $C_{I}$ are different for these two types of aerosols. $C_{I}$ is defined as by

$C_{I}=-\frac{\log \left(\beta_{532}^{A} / \beta_{355}^{A}\right)}{\log (355 \mathrm{~nm} / 532 \mathrm{~nm})}$ 


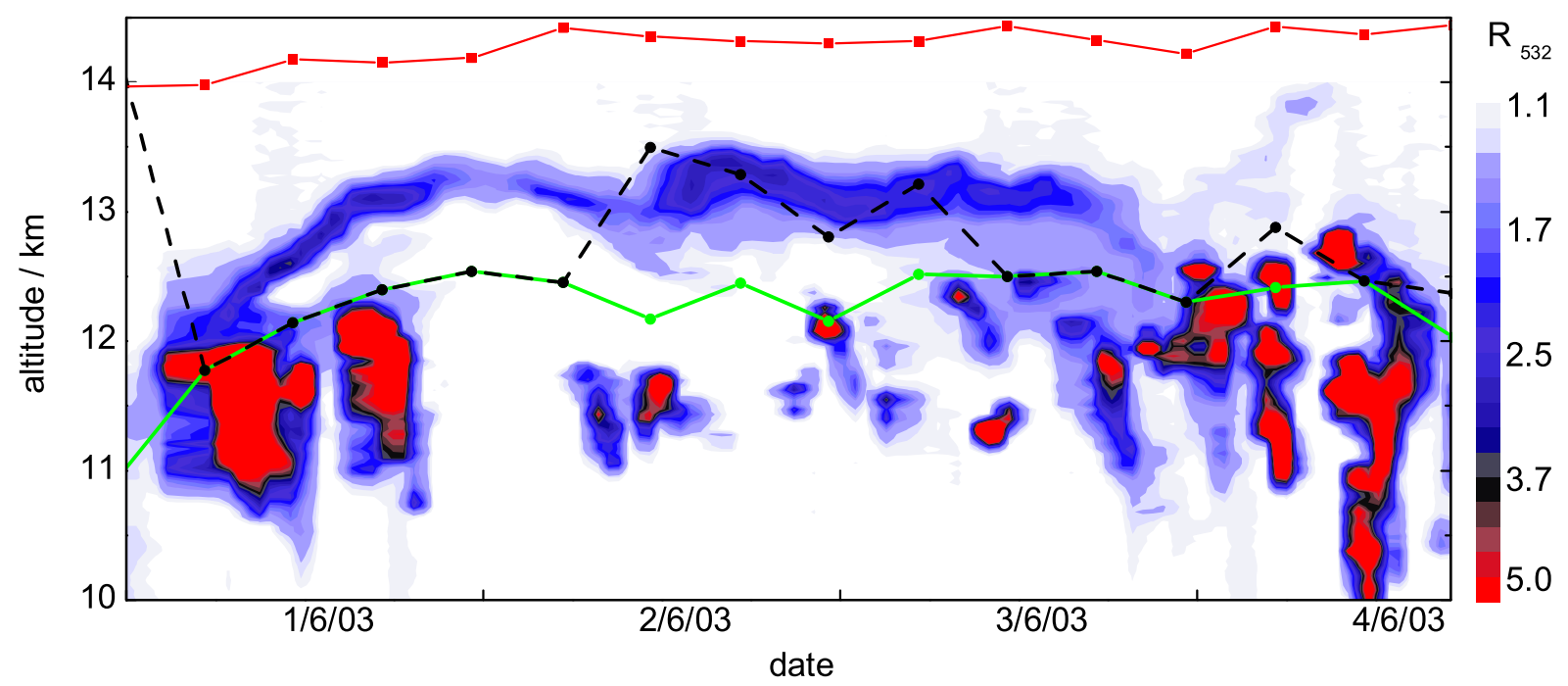

Fig. 3. Time-altitude plot of lidar backscatter ratio at $532 \mathrm{~nm}$ profiles measured in Lindenberg/Germany starting on 1 June 2003, 00:00 UT and ending on 4 June 2003, 17:00 UT. The solid green line indicates the altitude of the lapse rate tropopause determined from radiosonde launches four times a day. The dashed black line indicates the temperature minimum. The upper solid line in red marks the $380 \mathrm{~K}$ potential temperature level.

Based on the colour index and the lidar ratio $S$ defined as the ratio between the aerosol extinction and backscatter coefficient,

$S_{\lambda}=\frac{\alpha_{\lambda}^{A}}{\beta_{\lambda}^{A}}$

an estimate of the effective radius of the aerosol particles can be retrieved based on a method described in an earlier publication by Immler and Schrems (2003). Saharan dust has a large and wavelength dependent lidar ratio of about $40 \mathrm{sr}$ at $532 \mathrm{~nm}$ and $75 \mathrm{sr}$ at $355 \mathrm{~nm}$ and a small colour index of about zero or even below and shows significant depolarisation. Maritim aerosol on the contrary has a lower lidar ratio and does not depolarise. Urban and biomass burning aerosol have different optical properties and can be discriminated from the unpolluted types by its weak depolarisation, larger colour index $C_{I} \geq 1$ and a large lidar ratio of about $60-80 \mathrm{sr}$ at $532 \mathrm{~nm}$ (Wandinger et al., 2002). However, it is difficult to differentiate between urban and biomass burning aerosol on the basis of elastic backscatter lidar data since the differences in their optical properties are rather small and the variability of this properties due to aging, changes in relative humidity and other factors is relatively large.

\section{Observations of inelastic scattering by aerosols}

From April to October of 2003 we performed measurements at the Meteorological Observatory in Lindenberg $\left(52.2^{\circ} \mathrm{N}\right.$, $\left.14.1^{\circ} \mathrm{E}\right)$ near Berlin/Germany with the MARL. During this measuring campaign, strong layers of aerosol in the troposphere were frequently detected, and on several occasions we also observed layers of haze in the lower stratosphere. The most pronounced observation of this kind was made during the first days of June 2003, when a 0.4 to $1 \mathrm{~km}$ thick aerosol layer was dwelling at an altitude of about $13 \mathrm{~km}$ - about $1 \mathrm{~km}$ above the thermal tropopause - for more than $72 \mathrm{~h}$. Figure 1 shows the backscatter ratio $\mathrm{R}$ at $532 \mathrm{~nm}$ as a function of time and altitude from 1 June 2003 . $\mathrm{R}$ is the total atmospheric backscatter divided by the purely molecular contribution and thus a measure for the content of aerosol particles with 1 referring to a clear air. Between 4 and $8 \mathrm{~km}$ altitude some thin layers of aerosol are visible, around $12 \mathrm{~km}$ some scattered cirrus clouds are marked by strong backscatter $(R>5)$ above which a thin and steady layer emerges at about $12 \mathrm{~km}$ altitude. This layer persisted for the rest of the day, gaining altitude and stayed at $13 \mathrm{~km}$ throughout 2 June 2003 and most of 3 June 2003 (Fig. 3).

The tropopause was occasionally split during this period into a cold point tropopause (CPT) defined by the local temperature minimum and a lower lapse rate tropopause (LPT) as defined by the standard WMO definition according to which the tropopause is at the lowest level where the temperature gradient is higher than $-2 \mathrm{~K} / \mathrm{km}$ and the average of the gradient between this level and any level within the next $2 \mathrm{~km}$ is still higher than $-2 \mathrm{~K} / \mathrm{km}$. On the first day of the observation, 1 June 2003, LPT and CPT were at the same height, up to $1 \mathrm{~km}$ below the aerosol layer (Fig. 3). Around noon on 2 June 2003 the situation changed and a new temperature minimum appeared in $13.5 \mathrm{~km}$ altitude, just above the aerosol layer. The mean temperature in the aerosol layer itself decreased gradually from 213.5 to $209 \mathrm{~K}$ during the course of the three days (Fig. 5). 

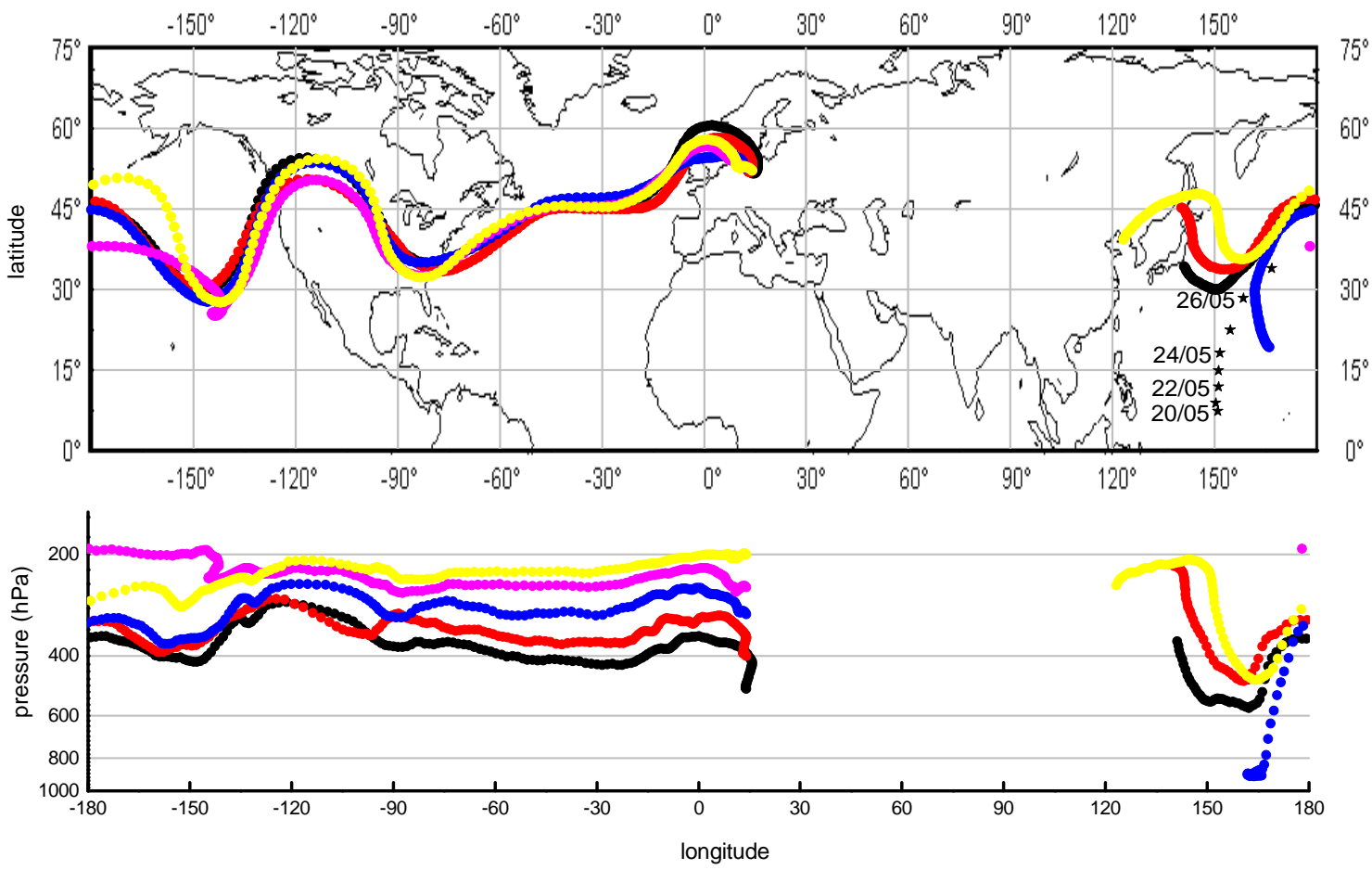

Fig. 4. 10-days-backward trajectories calculated for the location of Lindenberg on 3 June 2003, 00:00 UT. The asterisks mark the position of the typhoon 'Chan Hom' (from: http://weather.unisys.com/hurricane/w_pacific/2003/).

The aerosol layer at about $13 \mathrm{~km}$ is clearly above the tropopause but below the level of $380 \mathrm{~K}$ potential temperature (Figs. 3 and 6) which marks the border to the "overworld" where air can cross exclusively in the tropics (Holton et al., 1995). Therefore we assign the observed aerosol layer to the lowermost stratosphere. Backward trajectories on the basis of ECMWF data were retrieved using the BADC trajectory service (http://badc.nerc.ac.uk) with vertical advection based on the pressure vertical velocity $\omega$. The results for a 3 June 2003, 00:00 UT shown in Fig. 4 indicate that the air that we sampled in Lindenberg came from North America and has been travelling undisturbed across the Atlantic within five days. Trajectories calculated for other times between 1 June 2003, 12:00 UT and 3 June 2003, 18:00 UT yield very similar results.

The stratospheric aerosol layer was $650 \pm 300 \mathrm{~m}$ (mean \pm std. dev.) thick and the backscatter ratio of the layer varied in the range from 1.5 to 4 at $532 \mathrm{~nm}$. The optical depth at $532 \mathrm{~nm}$ determined from the nitrogen Raman signals varied from below 0.01 to $0.05(0.026 \pm 0.013)$. Within the accuracy of our measurements the values at $355 \mathrm{~nm}$ were about the same $(0.02 \pm 0.01)$. From these measurements the lidar ratio $S=\alpha / \beta$ can also be determined, yielding fairly high values of $86 \pm 30 \mathrm{sr}$ for $355 \mathrm{~nm}$ and $100 \pm 20 \mathrm{sr}$ for $532 \mathrm{~nm}$. The colour index $\left(C_{I}\right)$ of the layer with $1.0 \pm 0.2$ is rather constant throughout the whole period. The cloud shows a significant depolarisation (Fig. 6) with a clear diurnal cycle, reaching $20 \%$ during the day and dropping to $5 \%$ at night time (at $355 \mathrm{~nm}$ ). Using Mie scattering theory an estimate of the effective radius $r_{\text {eff }}$ can be retrieved from the colour index. Depending on whether we use the refractive index of water, ice, sulphate or dust (D'Almeida et al., 1991) for the retrieval, we find values between 0.1 and $0.4 \mu \mathrm{m}$. The number concentration of the layers is calculated to be 500 to $2000 \mathrm{~cm}^{-3}$ (based on an effective radius of $0.1 \mu \mathrm{m}$ ).

The optical properties that we measured are typical for an aged polluted aerosol (Wandinger et al., 2002) and therefore suggest absorbing, solid material containing soot emitted in urban regions or by biomass burning. The measured properties are different from typical values for dust, sea salt or sulphate. Finding aerosol of such properties in the lowermost stratosphere is an intriguing result, in particular with respect to the longevity of this layer. Nevertheless, there is one more very remarkable observation: Besides the backscatter ratio and temperature profiles, Fig. 5 shows the signal of the $407 \mathrm{~nm}$ channel of our instrument. During the nights of 1 June 2003 and 2 June 2003 (daytime measurements at $407 \mathrm{~nm}$ are not available) there is a peak at the altitude of the stratospheric aerosol layer at about $13 \mathrm{~km}$ (Fig. $5 \mathrm{~b}$ and c). This statistically significant signal was present throughout both nights, its strength correlated with the elastic backscatter signal of the aerosol layer.

As was demonstrated in Fig. 2 there is no cross talk from elastic backscatter into the $407 \mathrm{~nm}$ channel even in the 


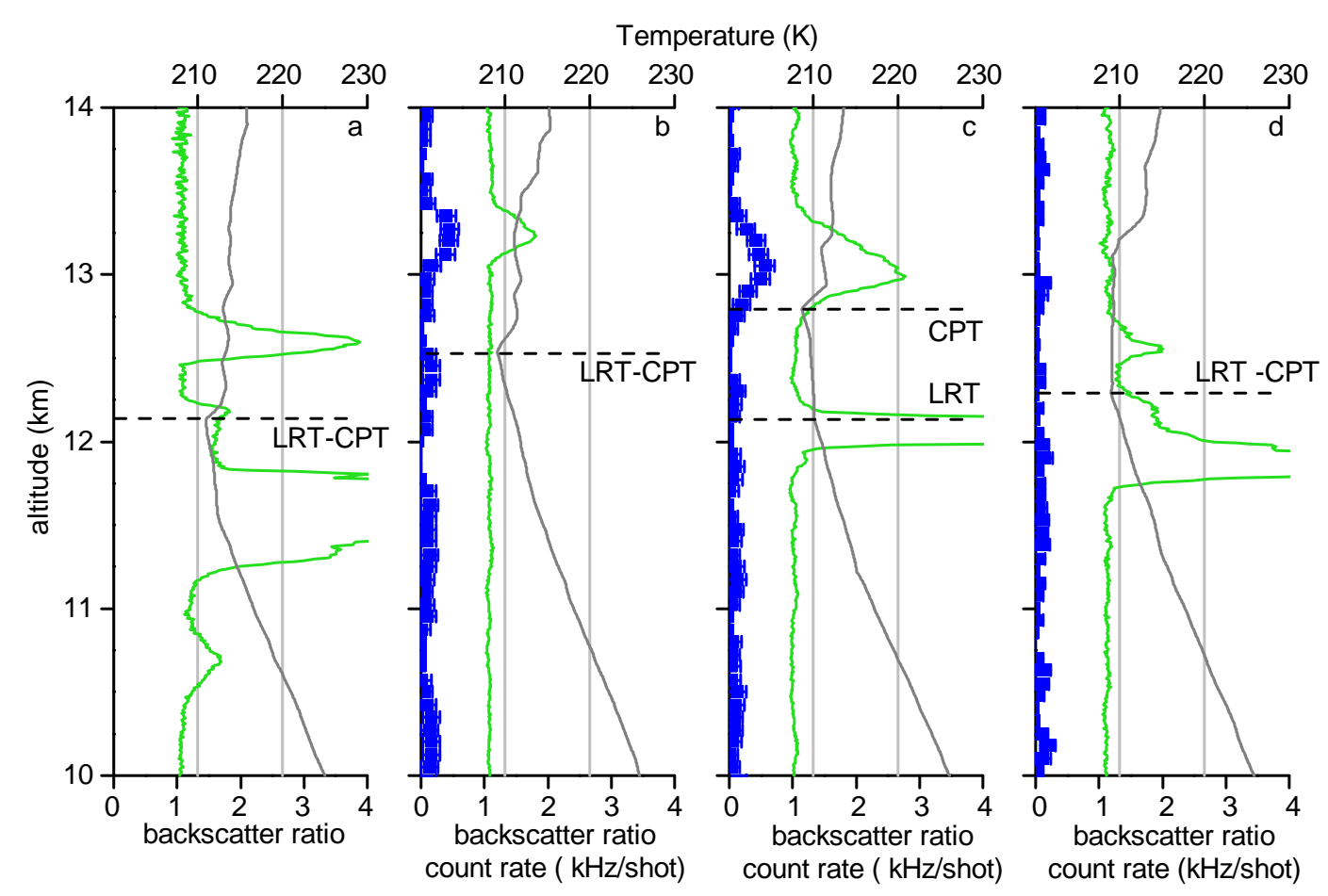

Fig. 5. Backscatter ratio profiles (green) measured on 1 June 2003, 11:00 UT (start time, a), 22:12 UT (b), 2 June 2003, $22: 22$ UT (c) and 3 June 2003, 21:31 UT (d) in Lindenberg by the lidar (36000 shots - 20 min mean). The temperature profiles measured at about the same time $(\delta t<60 \mathrm{~min})$ by a radiosonde is shown in grey lines. The dashed horizontal lines indicate the lapse rate (LRT) and the cold point tropopause (CPT). The blue curves show the raw signal detected in the $407 \mathrm{~nm}$ channel averaged over $75 \mathrm{~m}$ vertically.

presence of low clouds that give rise to very strong elastic backscatter. We have also never observed other unwanted effects in our Raman channel like after-pulsing or strong signal induced noise, that could explain the unusual signal at $13 \mathrm{~km}$ altitude (corresponding to a delay of $86 \mu$ s after the laser shoots). We therefore came to the conclusion that we detected inelastic scattering originating from the stratospheric aerosol layer. However, it was not clear in the first place what could cause such a strong inelastic signal at that altitude.

The simplest explanation is a high water vapour content in that plume. However, this explanation can be ruled out since the relative humidity above ice according to the calibrated $407 \mathrm{~nm}$ signal would be up to several thousand percent given the low temperature at the corresponding altitude. Even though high supersaturations have been observed in the atmosphere, such high values are not conceivable and definitely out of range, in particular in the presence of particles. Also, the radiosonde data does not indicate any enhancement of water vapour in that region (Fig. 6).

In the condensed phase, the Raman lines of $\mathrm{H}_{2} \mathrm{O}$ are widened to a rather broad band and shifted toward smaller wavelengths. The Raman spectrum of liquid cloud droplets overlaps with the spectrum of water vapour and thus with the transmission spectra of the filter in the $407 \mathrm{~nm}$ channel. Therefore, water clouds may interfere with Raman lidar mea- surements of water vapour (Melfi et al., 1997). However, there is strong evidence against the interpretation that the inelastic signals that we have measured were created by Raman scattering from water. First, the depolarisation shown in Fig. 6a indicates that the particles of the plume are solid and the Raman spectrum of ice does not overlap with the transmission of the filter we use in the $407 \mathrm{~nm}$ channel. Second, the Raman signal from condensed water is far to weak to be detected by our system. The size distribution retrieved from the elastic lidar backscatter as discussed above has a Volume density on the order of $10 \mu^{3} \mathrm{~cm}^{-3}$. If those particles were liquid water droplets the Raman backscattering coefficient would still be about 3 orders of magnitude below our detection limit even if we apply all the enhancement factors discussed by Melfi et al. (1997). In fact, we do not see any significant inelastic scattering from clouds, neither solid nor liquid, with our instrument. This is confirmed in Fig. 5c where the ice particles of the cirrus cloud at the tropopause, directly below the aerosol layer, do not create a detectable inelastic signal in the $407 \mathrm{~nm}$ channel, even though its elastic backscatter with a value of approximately 30 is by more than a factor of 10 higher compared to that of the aerosol layer above. This profile shows clearly, that neither cross talk from strong elastic backscatter, nor inelastic scattering from ice is measured by our system. We therefore came to 

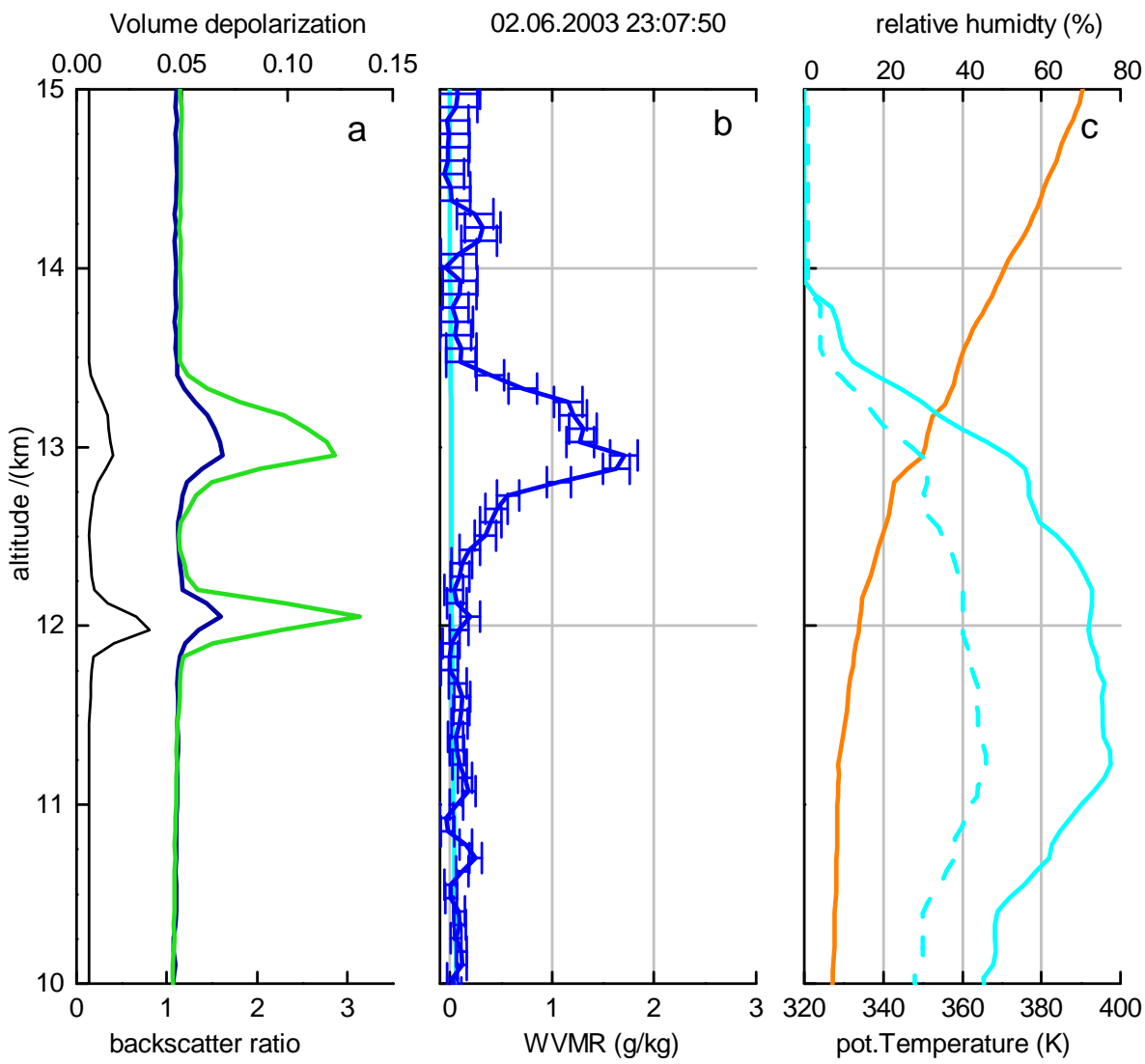

Fig. 6. Profiles from Lidar and radiosonde measurements from 2 June 2003 averaged from 22:44 to 23:07 UT. A radiosonde was launched at 22:45 UT and reached $13 \mathrm{~km}$ altitude at about 23:05 UT. The left plot shows the backscatter ratio at $532 \mathrm{~nm}$ (green) and $355 \mathrm{~nm}$ (blue). The black line indicates the Volume depolarisation. The plot in the middle displays the water vapour mixing ratio (WVMR) as determined by the calibrated lidar with a vertical resolution reduced to $75 \mathrm{~m}$ (blue) and the radiosonde (cyan). The bars indicate the total error derived from Poisson statistics and potential systematic errors (including a 5\% uncertainty from calibration). The right plot displays the relative humidity above ice (solid cyan) and above water (dashed) and the potential temperature (orange) from the radiosonde data.

the conclusion that the observed inelastic backscatter signal is a specific feature of the stratospheric aerosol layer and is not caused by water, neither liquid nor solid nor in the gas phase.

\subsection{Portuguese forest fire plumes}

While searching for other occasions where the water vapour Raman channel shows unexpected behaviour, we found a significant discrepancy between water vapour profiles measured with radiosonde and lidar during a number of consecutive days in early August 2003. A fairly strong layer of aerosol was present in these measurements throughout the troposphere with backscatter ratios up to 3 and the water vapour mixing ratio retrieved from the lidar data showed a systematic deviation from the moisture measurements of the radiosonde (Fig. 7b). During this period heavy forest fires were reported in Portugal. The backward trajectories shown in Fig. 8 give a clear indication, that the aerosol we detected in Lindenberg were smoke plumes from these forest fires.
Figure 7 shows on the right side the difference detected between the water vapour mixing ratio retrieved from the lidar data and those from the radiosonde. The error bars indicate the total error (including a 5\% uncertainty introduced by the calibration) and show that there is a significant positive bias in the lidar data. The differences between the lidar and the radiosonde data reach $1 \mathrm{~g} / \mathrm{kg}$ and are therefore much larger than the usual discrepancies (compare with Fig. 2). This bias correlates with the concentration of smoke aerosol that is displayed in green in terms of the elastic backscatter signal measured with the lidar. This correlation suggests, that the aerosol particles itself create the bias by inelastic scattering. The most likely explanation for this finding is laser induced fluorescence from aerosol particles. 
05 August 2003, 22:45 UTC

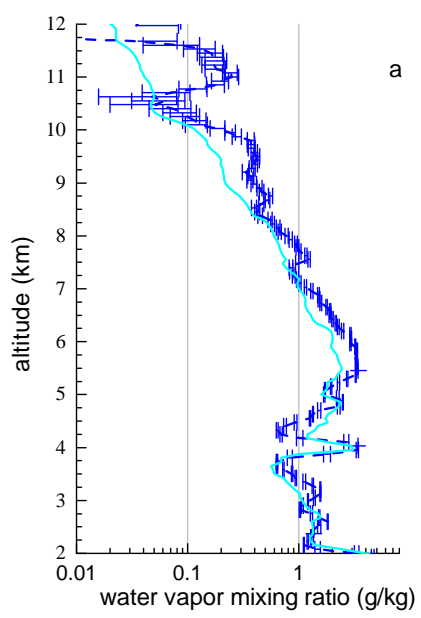

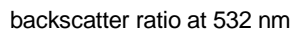

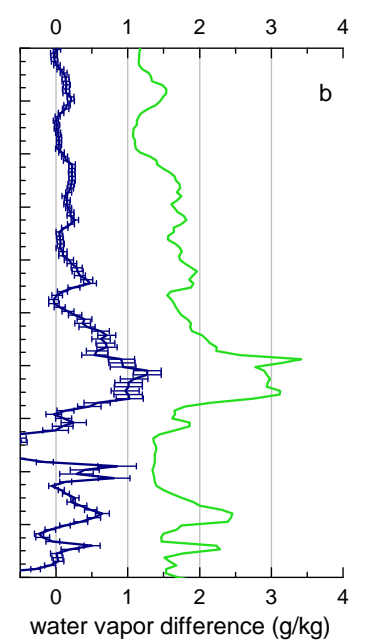

Fig. 7. Same as Fig. 2 measured on 5 August 2003, 22:38 UT.

\section{Discussion}

\subsection{Fluorescence in the atmosphere}

There is a long tradition of using laser induced fluorescence for lidar remote sensing of the atmosphere. Hydroxyl $(\mathrm{OH})$ and metal atoms such as sodium, potassium or iron have been detected by resonant fluorescence in the mesosphere in $85 \mathrm{~km}$ altitude and allow the determination of the temperature and wind at these altitudes (Neuber et al., 1988; von Zahn and Höffner, 1996; Brinksma et al., 1998). In the lower atmosphere however, fluorescence by atoms or molecules in the gas phase is severely hampered by collisional quenching of the exited states due to the high pressure. On the other hand fluorescence of mainly organic substances still allow interesting applications near or at the earth's surface. For instance, contamination of soils with petroleum products is detected in situ with high sensitivity using fluorescence (Schultze et al., 2004) and fluorescence lidars are used for remotely detecting oil spills, phytoplankton and chlorophyll on the surface of the sea (Cecchi et al., 2003).

The investigation of fluorescence from polycyclic aromatic hydrocarbons adsorbed on suspended particles was pioneered by Allegrini and Omenetto (1979) and the group of Niessner et al. (1991). The fluorescence spectra of Benzo[a]pyrene $\left(\mathrm{BaP}, \mathrm{C}_{20} \mathrm{H}_{12}\right)$ in water for example, shows a wide band covering the $407 \mathrm{~nm}$ region when excited at $355 \mathrm{~nm}$ (Fernández-Sánchez et al., 2003) and therefore could in principal be detected with the set-up used by our lidar. $\mathrm{BaP}$ is an ubiquitous product of incomplete combustion and is stable in the atmosphere. BaP and other PAHs adsorbed on soot in a smoke plume are known to persist for many days in the atmosphere (Behymer and Hites, 1988). In polluted air BaP was found in amounts of $200 \mathrm{pg} / \mathrm{m}^{-3}$ (Schauer et al., 2004). The presence of $\mathrm{BaP}$ and other PAHs in cigarette smoke is

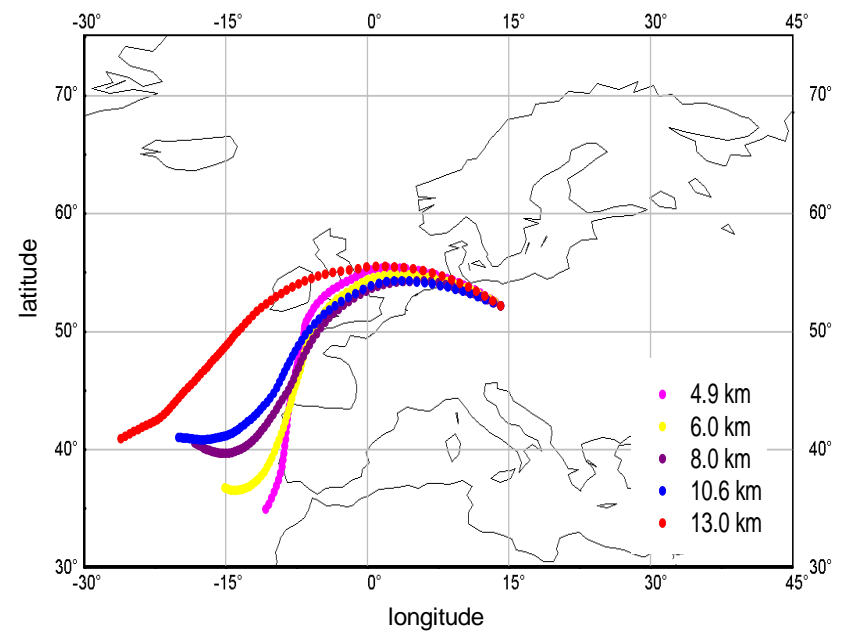

Fig. 8. 3-day-backward trajectories for Lindenberg, 6 August 2003, 00:00 UT at about which time the measurement of Fig. 7 was made. The different colours mark different altitude levels at the trajectories' end points as indicated in the legend.

not only one of the reasons for the carcinogenic effect of smoking, they are also the cause for the fluorescence exhibited by the smoke of tobacco leaves (Hill et al., 1999). This is one example for a biomass burning aerosol that fluoresces when irradiated with UV light.

A similar fluorescence spectrum such as the one from $\mathrm{BaP}$ was measured from bacteria and fungal spores (Hill et al., 1999). The detection and discrimination of biological particles in the atmosphere by their intrinsic fluorescence has received greater recognition in the recent years (Hairston et al., 1997). Besides in-situ detection, the remote detection of disseminated spores by a fluorescence lidar up to a distances of several kilometres have been reported (Christesen et al., 2004).

Another type of particles that shows fluorescence are sulphuric acid droplets which are contaminated with organic compounds. Hegglin et al. (2002) reported that they observed broad fluorescence spectra from single levitated sulphuric acid droplets that contained aliphatic hydrocarbon, alcohols, aldehydes, ketones or organic acids and conclude that ambient aerosol which often contain significant amount of these organics should fluoresce and thereby offer an interesting experimental possibility to identify biogenic material in aqueous droplets.

In considering these observations, we arrived at the conclusion that different types of biogenic material may have the potential to fluoresce at atmospheric conditions when excited with a laser beam like the one used in our lidar. But is it possible to detect such a signal from the lowermost stratosphere with the $407 \mathrm{~nm}$ channel? 
4.2 Detecting fluorescence of atmospheric aerosol with a lidar

To estimate the sensitivity of our instrument regarding the detection of fluorescence, we calculated the backscatter coefficient at $407 \mathrm{~nm} \beta_{407}(z)$ within the stratospheric aerosol layer. Based on the water vapour calibration discussed earlier, the backscatter coefficient measured with $407 \mathrm{~nm}$ channel can be calculated from Eq. (3) using the known scattering cross section $\sigma_{407}^{\mathrm{H}_{2} \mathrm{O}}$ of the $\mathrm{H}_{2} \mathrm{O}$ Raman line at $3657 \mathrm{~cm}^{-1}$ which is $8 \times 10^{-30} \mathrm{~cm}^{2} \mathrm{sr}^{-1}$ (Melfi et al., 1997). Accordingly, the peak at $13 \mathrm{~km}$ (Fig. 6b) corresponds to a backscatter coefficient in the order of $10^{-13} \mathrm{~cm}^{-1} \mathrm{sr}^{-1}$.

Unfortunately, little is reported about the cross sections of fluorophores like PAH on aerosol particles. Also, the efficiency of such a process in the atmosphere depends on many parameters including temperature and pressure hampering an assessment of the possibility of detecting the fluorescence from these agents by our lidar. However, measurements of cross sections of the fluorescence of bacteria and pollen are available, a value of $5 \times 10^{-14} \mathrm{~cm}^{2} \mathrm{~nm}^{-1}$ particle ${ }^{-1}$ for Bacillus globigii $(\mathrm{Bg})$ and $2 \times 10^{-13} \mathrm{~cm}^{2} \mathrm{~nm}^{-1}$ particle ${ }^{-1}$ for pine pollen when excited with light at $230 \mathrm{~nm}$ are reported by Stephens (1999). Given a scattering cross section in this order of magnitude, a concentration of fluorescing particles of about $0.1 \mathrm{~cm}^{-3}$ is calculated from the measured backscattered coefficient using Eq. (3). Given the concentration of particles estimated from the elastic backscatter which was about $1000 \mathrm{~cm}^{-3}$ this means that one out of $10^{4}$ particles in the plume should fluoresce in order to explain the inelastic signal that we have measured. The concentration of bacteria in ambient air is 0.001 to $0.01 \mathrm{~cm}^{-3}$ (Ariya and Amyot, 2003) and slightly below our limit of detection. An enhancement of bioparticles that may fluoresce is likely to occur in the plume of a forest fire. However, soot particles that fluoresce due to its content of $\mathrm{PAH}$ should be a lot more abundant than bioparticles and therefore might play a more important role for creating the fluorescence signal.

Hegglin et al. (2002) reported that the fluorescence signal of sulphuric acid droplets that are contaminated with organic material is 2-3 orders of magnitude higher than the Raman signal from the water stretching vibration that they were trying to measure in the first place. We discussed above, that the Raman signal from aqueous aerosol particles of an amount as inferred from the elastic lidar signals is about 3 orders of magnitude to weak to be detected with our lidar. Accordingly, the fluorescence of organic material could be strong enough to be measurable. The fluorescence of contaminated sulphuric acid droplets was reported to increase as the concentration increases and the aerosol ages (Hegglin et al., 2002). Therefore, in case of a dried and aged layer of particles in the lowermost stratosphere, the efficiency of fluorescence compared to Raman scattering should be particularly large.
This considerations demonstrate, that fluorescence should be taken into account when analysing Raman lidar signals in the presence of polluted air. Even though the information that is currently available is to scarce to give a detailed quantitative analysis, we are confident that fluorescence from organic material is the prime candidate to explain the inelastic scattering that we have detected from aerosol plumes in the troposphere and the lower stratosphere. The powerful laser, the large receiving telescope $(1.1 \mathrm{~m})$, and the large bandwidth $(5.7 \mathrm{~nm})$ and good performance of the $407 \mathrm{~nm}$ channel makes our system particularly suitable for detecting laser induced fluorescence from particles in the atmosphere. The decay time of the fluorescence signals of biologic material is on the order of $100 \mathrm{~ns}$ (Niessner et al., 1991). In lidar measurements this delay would be interpreted as an altitude shift of about $15 \mathrm{~m}$. The maximum vertical resolution of $7.5 \mathrm{~m}$ of the lidar and the naturally rather diffuse vertical structure of aerosol layers, leads us to the conclusion that the finite lifetime of the excited states of fluorophores has no discernible effect on the lidar measurements.

\subsection{Biomass burning aerosol in the stratosphere}

According to our investigation, the only agents capable to create the fluorescence that can interfere with the water vapour measurements of the lidar are organic compounds. The only case, where we have found tropospheric aerosol that creates such an interference is smoke from forest fires in Portugal. These facts lead us to the conclusion that the detection of fluorescence indicates aerosol of biogenic origin. Accordingly, the aerosol layer that we have observed in the lowermost stratosphere from 1 June 2003 to 3 June 2003 is must be contaminated with organic pollutants that came from a biomass burning event or something similar.

At that particular time, forest fires were abundant across the northern hemisphere, including an unprecedented 19 million hectares of boreal forest burned in Siberia (Damoah et al., 2004). Backward trajectories trace the air mass that we observed in Lindenberg back to the Pacific region where it obviously experienced convection (Fig. 4). Fromm et al. (2000) have suggested that extreme convection triggered by forest fires may be able to inject aerosol into the stratosphere at high latitudes. The origins of the trajectories in (Fig. 4) in the Pacific are detached from potential continental sources in Siberia and therefore do not support the idea of a direct injection of the forest fire smoke from thunderstorms created by the fires themselves. At that particular time a tropical storm, the Typhoon Chan Hom was active in that region and might have created a TST event that included polluted air from Asia (Fig. 4). A detailed model study of the history of the air mass and the possibility of TST events is beyond the scope of this work. However, it is conceivable that a fraction of the smoke from Siberian forest fires which has affected almost the entire northern hemisphere at that time (Damoah et al., 2004) emerged into the lower stratosphere. The fact that the elastic 
optical properties of this aerosol are those of an aerosol containing soot supports this hypothesis.

\section{Conclusions}

During a measuring campaign in Lindenberg/Germany we have detected inelastic scattering from an aerosol layer in the lowermost stratosphere. We showed that Raman scattering by water is not efficient enough to explain the observation and we are confident that the signal is not an instrumental artefact. Additionally, we presented results from water vapour measurements from August 2003 with our Raman lidar that show that aerosol particles related to Portuguese forest fires exhibit inelastic scattering. In the literature numerous reports describe the fluorescence of particles that are likely to be present in aerosol released by biomass burning. Fluorescence spectra of such particles are detectable by our lidar set-up. All these examples have in common, that organic compounds need to be present to create the fluorescence. Therefore, we conclude that atmospheric aerosol of biogenic origin may fluoresce when excited with a laser and that this fluorescence interfered with the water vapour measurement of the $407 \mathrm{~nm}$ Raman channel. The detection of fluorescence from atmospheric aerosol by a lidar has not yet been reported anywhere in literature, however, it is the most plausible explanation for our experimental results.

We interpret the fluorescence that we detected from aerosol layers as an indicator for particles created by biomass burning because both the events that we discussed were strongly linked to forest fires. It is still open which organic compounds could have caused the fluorescence and if particles from other sources may have similar properties. From the observations presented it is not possible to discriminate soot from contaminated sulphate, bioparticles or other possible fluorophores. Future lidar experiments should involve the detection of inelastic scattering at different wavelengths that are off the Raman line of water vapour. Such a set-up could discriminate fluorescence from water vapour Raman scattering without the need for additional measurements and therefore allows a unique identification of fluorescence of aerosol on the one hand and correction or rejection of the Raman lidar water vapour measurement due to fluorescence on the other hand. The measurements of vertically resolved fluorescence spectra of aerosol could become a helpful method for determining the type of particles. Additionally, quantitative laboratory measurements of the efficiencies of laser induced fluorescence created by aerosol particles of different types at different atmospheric conditions are necessary for a more detailed analysis of fluorescence lidar data.

The possibility of detecting fluorescence from atmospheric particles by lidar opens up new opportunities for remote sensing of the distribution and the composition of aerosols in the atmosphere and could therefore overcome some of the shortcomings of current techniques. These data are important prerequisites to assess the climatic impact of these types of anthropogenic aerosol, which is currently still debated (IPCC, 2001). Lidar techniques based on fluorescence detection could become a powerful tool to study the abundance of such aerosol as well as exchange processes between the upper troposphere and the lower stratosphere. Our observation of an aerosol layer lasting for three days above the tropopause, shows an interesting, rarely detected example of such an event in the tropopause region.

Acknowledgements. We like to thank the British Atmospheric data centre for providing access to ECMWF data and performing trajectory calculations. Thanks to I. Beninga, W. Ruhe (impres $\mathrm{GmbH}$ ) and the staff at MOL for assisting the experiments, to D. Kaiser and A. Schulz for supportive discussions.

Edited by: P. S. Monks

\section{References}

Allegrini, I. and Omenetto, N.: Laser-induced fluorescence and Raman scattering for real time measurement of suspended particulate matter, Env. Sci. Tec., 13, 349-350, 1979.

Ansmann, A., Wandinger, U., Riesbel, M., Weitkamp, C., and Michaelis, W.: Independent measurement of extinction and backscatter profiles in cirrus clouds by using a combined Raman elastic-backscatter lidar, Appl. Opt., 31, 7113-7131, 1992.

Ariya, P. and Amyot, M.: The role of bioaerosols in atmospheric chemistry and physics, Atmos. Environ., 38, 1231-1232, 2003.

Behymer, T. and Hites, R.: Photolysis of polycyclic aromatic hydrocarbons adsorbed on fly ash, Env. Sci. Tec., 22, 1311-1319, 1988.

Brinksma, E. J., Meijer, Y. J., McDermid, I. S., Cageao, R. P., Bergwerff, J. B., Swart, D. P. J., Ubachs, W., Matthews, W. A., Hogervorst, W., and Hovenier, J. W.: First lidar observations of mesospheric hydroxyl, Geophys. Res. Lett., 25, 51-54, 1998.

Brock, C. A., Hamill, P., Wilson, J. C., Jonsson, H. H., and Chan, K. R.: Particle formation in the upper tropical troposphere: A source of nuclei for the stratospheric aerosol, Science, 270, 1650-1653, 1995.

Cecchi, G., Lognoli, D., and Mochi, I.: Fluorecence lidars and their potentials for the remote sensing of the marine environment, Elsevier oceanography series, 69, 71-77, 2003.

Christesen, S., Merrow, C., DeSha, M., Wong, A., Wilson, M., and Butler, J.: UV fluoresence lidar detection of bioaerosols, SPIE, Vol. 2222, 228-237, 2004.

Chung, S. and Seinfield, J.: Global distribution and climate forcing of carbonaceous aerosols, J. Geophys. Res., 107, 4407, doi:10.1029/2001JD001397, 2002.

D’Almeida, G. A., Koepke, P., and Shettle, E. P.: Atmospheric Aerosols: global climatology and radiative characteristics, DEEPAK, 1991.

Damoah, R., Spichtinger, N., Forster, C., James, P., Mattis, I., Wandinger, U., Beirle, S., Wagner, T., and Stohl, A.: Around the world in 17 days - hemispheric-scale transport of forest fire smoke from russia in May 2003, Atmos. Chem. Phys., 4, 13111321, 2004,

SRef-ID: 1680-7324/acp/2004-4-1311. 
Fernández-Sánchez, J., Segura-Carretero, A., Costa-Fernández, J. M., Bordel, N., Pereiro, R., Cruces-Blanco, C., Sanz-Medel, A., and Fernández-Gutiérrez, A.: Fluorescence optosensors based on different transducers for the determination of polycyclic aromatic hydrocarbons in water, Ana. Bioana. Chem., 377, 614 623, 2003.

Fromm, M., Alfred, J., Hoppel, K., Hornstein, J., Bevilacqua, R., Shettle, E., Servranckx, R., Li, Z., and Stocks, B.: Observations of boreal forest fire smoke in the stratosphere by POAM III, SAGE II, and lidar in 1998, Geophys. Res. Lett., 27, 1407, doi:10.1029/2002GL016820, 2000.

Hairston, P., Ho, J., and Quant, F.: Design of an instrument for realtime detection of bioaerosols using simultaneous measurement of particle aerodynamic size and intrinsic fluorescence, J. Aeros. Sci., 28, 471-482, 1997.

Hegglin, M., Krieger, U., Koop, T., and Peter, T.: Technical note: Organics-induced fluorescence in Raman studies of sulfuric acid aerosols, Aero. Sci. Tech., 36, 510-512, 2002.

Hill, S. C., Pinnick, R. G., Niles, S., Pan, Y.-L., Holler, S., Chang, R. K., Bottiger, J., Chen, B., Orr, C.-S., and Feather, G.: Realtime measurement of fluorescence spectra from single airborne biological particles, Field A.C.T., 3, 221-239, 1999.

Holton, J. R., Haynes, P. H., McIntyre, M. E., Douglass, A. R., Rood, R. B., Pfister L.: Stratosphere-troposphere exchange, Rev. Geophys., 33, 403-439, 1995.

Immler, F. and Schrems, O.: Vertical profiles, optical and microphysical properties of Saharan dust layers determined by a shipborne lidar, Atmos. Chem. Phys., 3, 1353-1364, 2003,

\section{SRef-ID: 1680-7324/acp/2003-3-1353.}

IPCC: Third Assessment report - Climate Change, Cambridge University press, 2001.

Jost, H.-J., Drdla, K., Stohl, A., Pfister, L., Loewenstein, M., Lopez, J. P., Hudson, P. K., Murphy, D. M., Cziczo, D. J., Fromm, M., Bui, T. P., Dean-Day, J., Gerbig, C., Mahoney, M. J., Richard, E. C., Spichtinger, N., Pittman, J. V., Weinstock, E. M., Wilson, J. C., and Xueref, I.: In-situ observations of mid-latitude forest fire plumes deep in the stratosphere, Geophys. Res. Lett., 31, L11 101, doi:10.1029/2003GL019253, 2004.

Kaufman, Y. J., Haywood, J. M., Hobbs, P. V., Hart, W., Kleidman, R., and Schmid, B.: Remote sensing of vertical distributions of smoke aerosol off the coast of africa, Geophys. Res. Lett., 30, 1831-1834, 2002.

Leiterer, U., Dier, H., and Naebert, T.: Improvements in radiosonde humidity profiles using RS80/RS90 radiosondes of Vaisala, Beiträge zur Physik der Atmosphäre, 70, 4, 319-336, 1997.
Melfi, S.: Remote measurements of the atmosphere using Raman scattering, Appl. Opt., 11, 1605-1610, 1972.

Melfi, S. H., Evans, K., Li, J., Whiteman, D., Ferrare, R., and Schwemmer, G.: Observation of Raman scattering by cloud droplets in the atmosphere, Appl. Opt., 36, 3551-3559, 1997.

Neuber, R., von der Gathen, P., and von Zahn, U.: Altitude and temperature of the mesopause at $69^{\circ} \mathrm{N}$ latitude in winter, J. Geophys. Res., 93, 11 093-11 101, 1988.

Niessner, R., Robers, W., and Krupp, A.: Detection of particulate polycyclic aromatic hydrocarbons by laser-induces timeresolved fluorescence, Fresenius J. Anal. Chem., 341, 207-213, 1991.

Schäfer, H.-J., Schrems, O., Beyerle, G., Hofer, B., Mildner, W., Theopold, F., Lahmann, W., Weitkamp, C., and Steinbach, M.: A modular and mobile, multi-purpose lidar system for observation of tropospheric and stratospheric aerosols, SPIE EurOpto Series, 2581, 128-136, 1995.

Schauer, C., Niessner, R., and Pöschl, U.: Analysis of nitrated polyaromatic hydrocarbons by liquid chromatography with fluorescence and mass spectrometry detection: air particulate matter, soot and reaction product studies, Ana. Bioana. Chem., 378, 725-736, 2004.

Schultze, R., Lemke, M., and Löhmannsröben, H.-G.: Laserinduced fluorescence (lif) spectroscopy for the in situ analysis of petroleum product-contaminated soils, in: Laser in environmental and life science, edited by: Hering, P., Lay, J. P., and Stry, S., Springer, 79-98, 2004.

Stephens, J.: Measurements of the ultraviolet fluorescence cross sections and spectra of bacillus anthracis simulants, Final report, LOS ALAMOS NATIONAL LAB NM, 48, 1999.

von Zahn, U. and Höffner, J.: Mesopause temperature profiling by potassium lidar, Geophys. Res. Lett., 23, 141-144, 1996.

Wandinger, U., Müller, D., Böckmann, C., Althausen, D., Matthias, V., Bösenberg, J., Weiss, V., Fiebig, M., Wendisch, M., Stohl, A., and Ansmann, A.: Optical and microphysical characterization of biomass-burning and industrial-pollution aerosols from multiwavelength lidar and aircraft measurements, J. Geophys. Res., 107, 8125, doi:10.1029/2000JD000202, 2002.

Whiteman, D. N., Melfi, S. H., and Ferrare, R.: Raman lidar system for the measurement of water vapor and aerosols in the earth's atmosphere, Appl. Opt., 31, 3068-3082, 1992. 